\title{
Hydrocarbon-degradation by isolate Pseudomonas lundensis UTAR FPE2
}

\author{
Adeline, S. Y. Ting, ${ }^{*}$ Carol, H. C. Tan and Aw, C. S. \\ Faculty of Engineering and Science, Universiti Tunku Abdul Rahman, \\ Jalan Genting Kelang, Setapak 53300, Kuala Lumpur, Malaysia \\ E-mail:tingsy@utar.edu.my
}

Received 17 January 2009; received in revised form 16 June 2009; accepted 17 June 2009

\begin{abstract}
In this study, the potential of isolate Pseudomonas lundensis UTAR FPE2 as a hydrocarbon degrader was established. Their biodegradation activity was first detected with the formation of clearing zones on Bushnell-Hass agar plates, with the largest diameter observed on plates supplemented with paraffin, followed by mineral oil and petrol. Utilization of hydrocarbon sources were again detected in broth cultures supplemented with similar hydrocarbon substrates, where the mean viable cell count recovered from hydrocarbon-supplemented broth cultures were higher than the initial inoculum except for napthalene. In both tests, the isolate showed higher degradability towards aliphatic hydrocarbon sources, and the least activity towards the aromatic hydrocarbon naphthalene. The isolate P. lundensis UTAR FPE2 (8 $\log _{10} \mathrm{cfu} / \mathrm{mL}$ ) also degraded crude diesel sample, with $69 \%$ degradation during the first three days. To conclude, this study suggests the potential use of this isolate for bioremediation of hydrocarbon-contaminated environments.
\end{abstract}

Keywords: bioremediation, crude diesel, hydrocarbon-degrading bacteria, Pseudomonas lundensis

\section{INTRODUCTION}

Biodegradation is a biologically catalyzed reduction process of complex chemicals. This process, performed by a variety of bacteria, fungi and yeasts, transforms potentially toxic compounds into non-toxic compounds to obtain energy and nutrients (Alexander, 1994; Scragg, 2001). Biodegradation is essential in crude oil bioremediation as it is one of the primary ways by which crude oil is eliminated from the contaminated sites (Leahy and Colwell, 1990; Yuste et al., 2000). Therefore, microorganisms which are able to degrade hydrocarbon have vast potential in crude oil bioremediation.

Most of the microorganisms in the environment are alkane-degraders (Roubal and Atlas, 1978; Foght et al., 1990), but it is the isolates that can degrade both aliphatic and aromatic hydrocarbons that are highly desirable, especially since crude oil comprises mostly alkanes (Atlas, 1981), monocyclic hydrocarbons (Scragg, 2001), aromatic hydrocarbons (Focht and Westlake, 1987), resins and asphaltenes (Leahy and Colwell, 1990). One of the most extensively studied species of hydrocarbondegraders is the Pseudomonas species, known to degrade crude oil (Benkacoker and Ekundayo, 1996), diesel (Bento et al., 2003), and a variety of polycyclic aromatic hydrocarbons (Deziel et al., 1996). Among the many Pseudomonas species, $P$. aeruginosa (ljah and Antai, 2003), P. alcaligenes (O'Mahony et al., 2006) and $P$. putida (Raghavan and Vivekananda, 1999; Marques and Ramos, 1993) are more thoroughly investigated and their effectiveness as bioremediative agents for hydrocarbon bioremediation is well-established.

In our study, we successfully isolated a Pseudomonas isolate from the fuel (diesel) tank of a lorry. We characterized this isolate and performed in vitro tests to detect its biodegradation potential on several hydrocarbon sources. The efficacy of this isolate in biodegrading crude diesel sample was also established. This paper reports the results of the tests conducted, and suggests the potential of this isolate as a bioremediative agent for hydrocarbon bioremediation.

\section{MATERIALS AND METHODS}

\section{Isolate preparation and characterization}

Isolate UTAR FPE2 was isolated from the fuel (diesel) tank of a lorry. The isolate was maintained on Nutrient Agar (NA) (Oxoid) plates and incubated for $48 \mathrm{~h}$ at $27 \pm 2$ ${ }^{\circ} \mathrm{C}$ prior to use. A standard curve for this isolate was also established. For characterization, cultural and morphological characteristics were examined based on a $24 \mathrm{~h}$-old culture on NA. In addition, isolate UTAR FPE2 was also identified using BIOLOG.

\section{Detection of hydrocarbon-degrading activity}

Detection of hydrocarbon-degrading activity was first performed using the Bushnell-Haas $(\mathrm{BH})$ plate assay, which detects hydrocarbon-degrading activity based on the diameter of clearing zones formed around the 
bacterial colonies (Zhang et al., 2004). The BH agar plates were incorporated with one of the following carbon sources prior to solidification; $5 \%(\mathrm{v} / \mathrm{v})$ mineral oil (Fluka), $5 \%(\mathrm{v} / \mathrm{v})$ paraffin $\left(\right.$ Systerm $\left.{ }^{\circledR}\right)$, or $10 \%(\mathrm{v} / \mathrm{v})$ petrol (Mobil). Each carbon source was added separately into the corresponding plates. A loopful of the bacterium was then inoculated on the agar and the inoculated plates were sealed with parafilm, and incubated at $30 \pm 2{ }^{\circ} \mathrm{C}$ for 7 days. Diameter of clearing zones formed on the agar was measured daily and the mean diameter of clearing zone and the increase of diameter/day were calculated.

To further determine the biodegradation efficacy of isolate UTAR FPE2, testing using broth cultures were conducted. Sterile test tubes containing $10 \mathrm{~mL}$ of sterilized Nutrient Broth (NB) was supplemented with $1 \mathrm{~mL}$ of mineral oil, paraffin, naphthalene and petrol, separately. Naphthalene was dissolved in $5 \%(\mathrm{w} / \mathrm{v})$ diethyl ether prior to incorporation into NB. All the carbon sources used were filter-sterilized using cellulose-nitrate membrane filter $(0.45 \mu \mathrm{m}$, Sartorius) before addition into the tubes. A separate tube containing $10 \mathrm{~mL}$ of NB served as control. Each tube was then inoculated with $1 \mathrm{~mL}$ of bacterial inoculum $\left(6 \log _{10} \mathrm{cfu} / \mathrm{mL}\right)$. All the tubes were incubated for $72 \mathrm{~h}$ at $30 \pm 2{ }^{\circ} \mathrm{C}$. After incubation, the absorbance values for cultures from the test tubes were read at $640 \mathrm{~nm}$. Absorbance value reflects the bacterial growth upon utilization (degradation) of the tested hydrocarbon types as the sole carbon source (Li et al., 2000). The bacterial growth was estimated based on the absorbance value and expressed as cfu/mL from the standard curve.

\section{Biodegradation efficacy on diesel}

The biodegradation potential of isolate UTAR FPE2 on diesel (Mobil) was evaluated. Diesel was selected as this isolate was initially isolated from the diesel tank of a lorry, thus may have better degradation activity on diesel. One $\mathrm{mL}$ of the bacterial inoculum (8 $\left.\log _{10} \mathrm{cfu} / \mathrm{mL}\right)$ was inoculated into test tubes containing $8.0 \mathrm{~mL}$ of sterilized distilled water supplemented with $1.0 \mathrm{~mL}$ of diesel. Two controls were prepared. The first control treatment was achieved by incorporating $1.0 \mathrm{~mL}$ of diesel into $9.0 \mathrm{~mL}$ of sterilized distilled water. The second control treatment was prepared by mixing $9.0 \mathrm{~mL}$ of sterilized distilled water with $1.0 \mathrm{~mL}$ of bacterial suspension. All the tubes were sealed with parafilm and kept in the dark at $27 \pm 2{ }^{\circ} \mathrm{C}$ for 7 days.

To determine degradation efficacy, the diesel layer was first extracted with $9 \mathrm{~mL}$ of diethyl ether (Systerm), diluted $10^{4}$ times and the absorbance read at $225 \mathrm{~nm}$. The biodegradation efficacy (BE) was calculated using the following formula by Michaud et al. (2004):

$\operatorname{BE}(\%)=100-\left(A_{s} / A_{a c} \times 100\right)$

where, $A_{s}$ represents absorbance value of tested samples, and $A_{a c}$ represents the absorbance value of control samples.

\section{Statistical analysis}

The experiment was conducted with each test having three replicates. The analysis of variance (ANOVA) and means comparison were achieved using SAS (Statistical Analysis System) version 6.12.

\section{RESULTS AND DISCUSSION}

Cultural and morphological characteristics indicated that isolate UTAR FPE2 is from the genus Pseudomonas. The bacterium is rod-shaped, forming shiny mucoid colonies with umbonate elevation on NA plates. Isolate also showed catalase positive, with negative Gram-staining and did not produce endospore. Colonies produced pigmentation which turned the agar green fluorescent (data not shown). BIOLOG identification system identified the isolate as Pseudomonas lundensis.

Previous literatures mostly showed that Pseudomonas lundensis is commonly associated with the spoilage of milk, cheese, meat and fish (Gennari and Dragotto, 1992; Tryfinopoulou et al., 2002) and their isolation from other sources and hydrocarbon-degradation potential has not been documented. As a member of the Pseudomonas spp., they are naturally ubiquitous, and their ability to utilize almost any organic compounds has propelled their importance in many cycles, especially in carbon cycles, and in this study, the isolate is related to the hydrocarbon cycle. In addition, our sampling results also proved that $P$. lundensis can be isolated from other samples such as the diesel tank of a lorry, apart from spoiled meat or fish. As such, this may be the first few reports to highlight their hydrocarbon-degrading potential.

The biodegradation activity of $P$. lundensis UTAR FPE2 was evident in both $\mathrm{BH}$-plate assay and broth culture assessments. In $\mathrm{BH}$-plate assay, the mean diameter of clearing zone produced was largest on agar supplemented with paraffin, followed by mineral oil and petrol with $3.11 \mathrm{~cm}, 2.73 \mathrm{~cm}$ and $1.45 \mathrm{~cm}$, respectively (Figure 1). The calculated mean of biodegradation rate showed similar results, with the fastest degradation rate detected on the substrate paraffin, with clearing zones formed at $0.56 \mathrm{~cm} /$ day, followed by $0.51 \mathrm{~cm} /$ day and 0.48 $\mathrm{cm} /$ day on $\mathrm{BH}$-agar supplemented with mineral oil and petrol, respectively (Figure 2). Biodegradation of petrol was the slowest, as the clearing zone only appeared by day 4 of inoculation. We determined that the rate of increase in diameter that is formed corresponds to the rate of biodegradation of the isolate on a specific hydrocarbon source. As such, we were able to conclude that isolate $P$. lundensis UTAR FPE2 was a fast degrader of paraffin, followed by mineral oil and petrol.

We did not observe formation of clearing zone on $\mathrm{BH}$ agar supplemented with naphthalene. Zhang et al. (2004) who observed similar results reasoned that clear zones were not visible in naphthalene solid cultures because this substrate is highly volatile. Degradation of naphthalene was only detected in the broth culture assessment with a mean viable cell count of $5.81 \log _{10} \mathrm{cfu} / \mathrm{mL}$. The cell count was the poorest among the hydrocarbon-substrates 
tested. Higher number of viable cells, that is $6.56 \log _{10}$ $\mathrm{cfu} / \mathrm{mL}, 6.62 \log _{10} \mathrm{cfu} / \mathrm{mL}$, and $6.41 \log _{10} \mathrm{cfu} / \mathrm{mL}$ were recovered from broth supplemented with paraffin, mineral oil and petrol, respectively (Figure 3). Therefore the results here confirmed our earlier observation on $\mathrm{BH}$-plate assay that isolate $P$. lundensis UTAR FPE2 has higher degradability towards aliphatic groups (mineral oil and paraffin) compared to the aromatic naphthalene. The preference on aliphatics (mineral oil, paraffin) over aromatics (naphthalene) is attributed to the predominance of aliphatics over aromatics in bacterial mineralization (Foght et al., 1990; Li et al., 2000). As a result, the degradation of the aliphatic over aromatic fraction is naturally faster as also observed in this study. Furthermore, aromatic naphthalene is not easily degradable because of its complexity in structural composition of the molecules (Chaillan et al., 2004).

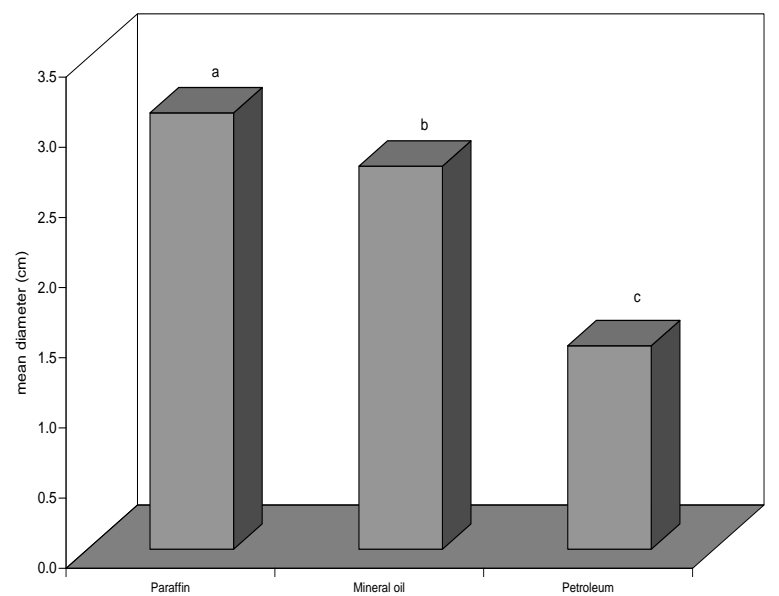

Figure 1: Mean diameter of clearing zones detected on $\mathrm{BH}$ agar plates supplemented with paraffin, mineral oil and petrol. Means with the same letters are not significantly different $\left(\mathrm{HSD}_{(0.05)}\right)$.

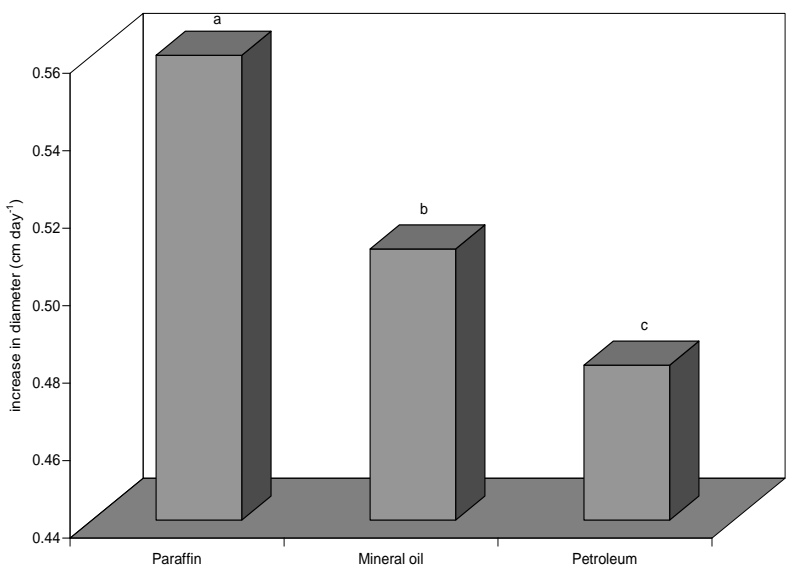

Figure 2: Calculated mean increase in diameter of clearing zones based on observations on $\mathrm{BH}$ agar plates supplemented with paraffin, mineral oil and petrol. Means with the same letters are not significantly different $\left(\mathrm{HSD}_{(0.05)}\right)$.

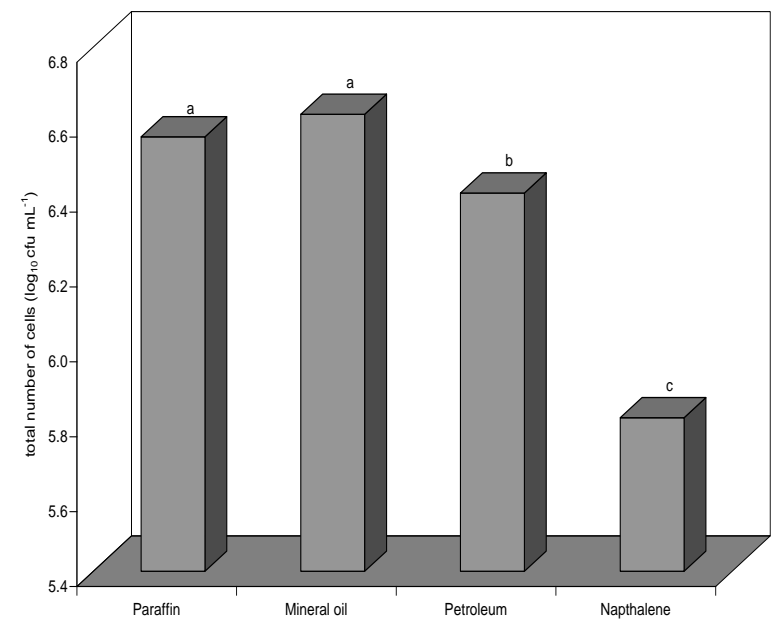

Figure 3: Mean total number of viable cells recovered from broth cultures supplemented with various hydrocarbon substrates. Means with the same letters are not significantly different $\left(\mathrm{HSD}_{(0.05)}\right)$.

The degradation efficacy of isolate $P$. lundensis UTAR FPE2 on crude diesel showed rapid degradation in the first three days, with mean of $69 \%$ biodegradation efficacy. However, from day 4 onwards, mean percentage of biodegradation efficacy decreased to less than $50 \%$ (Figure 4). Nevertheless, the increase in diesel biodegradation during the first three days benefited the isolate as more viable cells were recovered (Figure 5). Presence of diesel also sustained growth of bacterial isolate throughout the 7 days, resulting in higher mean of viable cell count of $6.67 \log _{10} \mathrm{cfu} / \mathrm{mL}$, compared to treatments without diesel which recorded $6.56 \log _{10}$ $\mathrm{cfu} / \mathrm{mL}$. At the end of 7 days, viable cell count for treatment with diesel was significantly higher with $7.2 \log _{10}$ $\mathrm{cfu} / \mathrm{mL}$ compared to $5.88 \log _{10} \mathrm{cfu} / \mathrm{mL}$ recovered from treatment without diesel (Figure 5).

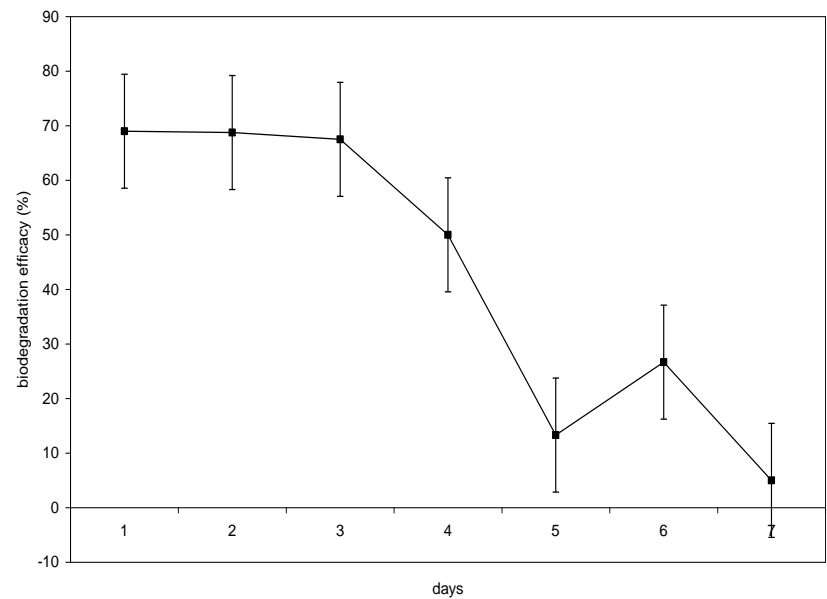

Figure 4: Biodegradation percentage of isolate UTAR FPE2 as a function of incubation time (days). Bars indicate standard error of means. 


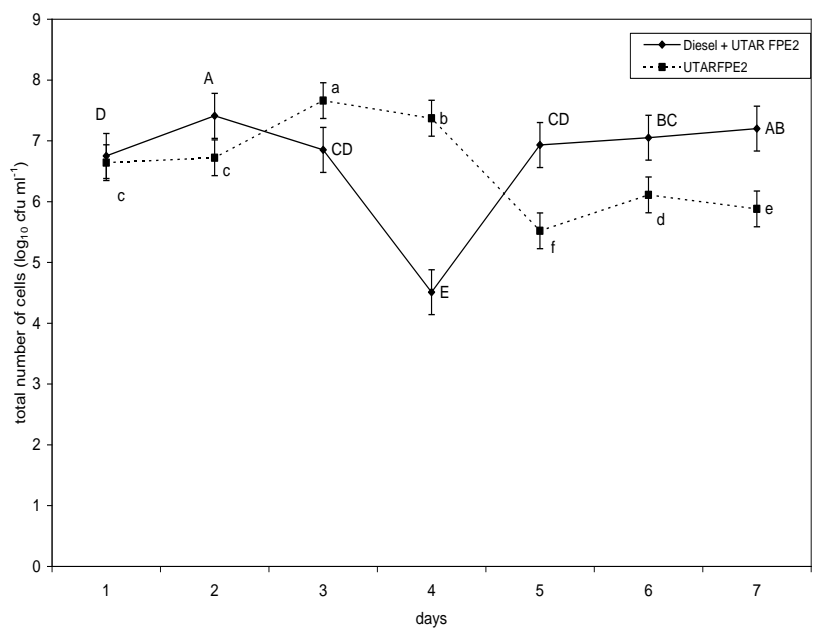

Figure 5: Total number of viable cells recovered from treatments with and without diesel. Bars indicate standard error of means. Means with the same letters in the same caption are not significantly different $\left(\mathrm{HSD}_{(0.05)}\right)$.

The results here showed the possible reaction when the isolate $P$. lundensis UTAR FPE2 is used to bioremediate diesel pollutants in the environment. Crude diesel was readily degraded by the isolate, an indigenous bacterium isolated from diesel tank. This isolate may have similar metabolic profiles with most hydrocarbondegraders which could metabolize long-chain-length of alkanes efficiently but not PAH (Yuste et al., 2000). Although the results are preliminary, the isolate $P$. lundensis UTAR FPE2 showed significant potential with $69 \%$ degradation activity for the first three days. The biodegradation activities helped to sustain bacterial growth, and despite the reduction of biodegradation activity in the following days, presumably due to the depleted hydrocarbon substrate, the viability of cells were not affected. This may suggest that the bacteria can continue to survive even in the absence of diesel. Nevertheless, their viability, efficacy and response to the depleting hydrocarbon source are still inconclusive and remain to be investigated.

\section{CONCLUSIONS}

This study showed that the isolate Pseudomonas lundensis UTAR FPE2 has the potential for usage in removing hydrocarbon substrates, such as diesel from the environment. Although known primarily as a spoilage agent in meat and fishes, their ability to degrade hydrocarbon was documented here. Their efficacy in biodegrading various types of hydrocarbon sources (aliphatic, aromatic and mixed hydrocarbon), albeit with varying degrees of efficacy were also established. Further studies such as up-scaling to batch experiments to determine their efficacy can be performed, especially on more types of hydrocarbon samples.

\section{ACKNOWLEDGEMENT}

The authors acknowledge the CABI Southeast and East Asia for their assistance in identifying the isolate.

\section{REFERENCES}

Alexander, M. (1994). Biodegradation and Bioremediation. Academic Press: New York, pp. 480.

Atlas, R. M. (1981). Microbial degradation of petrol hydrocarbons: An environmental perspective. Microbial Review 45, 180-209.

Benkacoker, M. O. and Ekundayo, J. A. (1996). Applicability of evaluating the ability of microbes isolated from an oil spill site to degrade oil. Environmental Monitoring and Assessment 45, 259272.

Bento, F. M., Camargo, F. A., Okeke, B. and Fankenberger, W. T. (2003). Bioremediation of soil contaminated by diesel oil. Brazillian Journal of Microbiology 34, 65-68.

Chaillan, F., Fleche, A. L., Bury, E., Phantavong, Y. H., Grimont, P., Saliot, A. and Oudot, J. (2004). Identification and biodegradation potential of tropical aerobic hydrocarbon-degrading microorganisms. Research in Microbiology 155, 587-595.

Deziel, A., Paquete, G., Villemur, R., Lepine, F. and Bisaillon, J. G. (1996). Biosurfactant production by a soil Pseudomonas strain growing on polycyclic aromatic hydrocarbons. Applied Environmental Microbiology 62, 908-912.

Foght, J. M. and Westlake, D. W. S. (1987). Biodegradation of hydrocarbons in freshwater. In: Oil in Freshwater: Chemistry, Biology, Countermeasure Technology. Vandermeulen H. (ed). Pergamon Press, New York. pp. 217-230.

Foght, J. M., Fedorak, P. M. and Westlake, D. W. S. (1990). Mineralization of ['4C] hexadecane and ['4C] phenanthrene in crude oil: specificity among bacterial isolates. Canadian Journal of Microbiology 36, 169175.

Gennari, M. and Dragotto, F. (1992). A study of the incidence of different fluorescent Pseudomonas species and biovars in the microflora of fresh and spoiled meat and fish, raw milk, cheese, soil and water. Journal of Applied Bacteriology 72, 281-288.

Ijah, U. J. J. and Antai, S. P. (2003). The potential use of chicken drop microorganism for oil spill remediation. The Environmentalist 23, 89-95.

Leahy, J. G. and Colwell, R. R. (1990). Microbial degradation of hydrocarbons in the environment. Microbial Review 53, 305-315.

Li, G., Huang, W., Lerner, D. N. and Zhang, X. (2000). Enrichment of degrading microbes and bioremediation of petrochemical contaminants in polluted soil. Water Resource 34, 3845-3853.

Marques, S. and Ramos, J. L. (1993). Transcriptional control of the Pseudomonas putida TOL plasmid catabolic pathways. Molecular Microbiology 9, 923929. 
Michaud, L., Giudice, A. L., Saitta, M., Domenico, M. D. and Bruni, V. (2004). The biodegradation efficiency on diesel oil by two psychrotrophic Antarctic marine bacteria during a two-month-long experiment. Marine Pollution Bulletin 45, 405-409.

O'Mahony, M. M., Dobson, A. D. W., Barnes, J. D. and Singleton, I. (2006). The use of ozone in the remediation of polycyclic aromatic hydrocarbon contaminated soil. Chemosphere 63, 307-314.

Raghavan, P. U. M. and Vivekanandan, M. (1999). Bioremediation of oil-spilled sites through seeding of naturally adapted Pseudomonas putida. International Biodeterioration and Biodegradation 44, 29-32.

Roubal, G. and Atlas, R. M. (1978). Distribution of hydrocarbon utilizing microorganisms and hydrocarbon biodegradation potentials in Alaskan continental shelf areas. Applied Environmental Microbiology 35, 897-905.

Scragg, A. (2001). Environmental biotechnology. Oxford University Press Inc., New York. pp. 456.

Tryfinopoulou, P., Tsakalidou, E. and Nychas, G. J. E. (2002). Characterization of Pseudomonas spp. associated with spoilage of gilt-head sea bream stored under various conditions. Applied Environmental Microbiology 68, 65-72.

Yuste, L., Corbella, M. E., Turiegano, M. J., Karlson, U., Puyet, A. and Rojo, F. (2000). Characterization of bacterial strains able to grow on high molecular mass residues from crude oil processing. FEMS Microbiology Ecology 32, 69-75.

Zhang, H., Kallimanis, A., Koukkou, A. I. and Drainas, C. (2004). Isolation and characterization of novel bacteria degrading polycyclic aromatic hydrocarbons from polluted Greek soils. Applied Microbiology Biotechnology 65, 124-131. 